\title{
A New Modified Postero-Inferior Technique in Management of Grade III Gynecomastia
}

\author{
MOHAMED A. GHANEM, M.D.; AHMED S. HWEIDI, M.D. and ADEL H. AMR, M.D. \\ The Department of Plastic, Reconstruction, Maxillofacial Surgeries and Burn Management, Faculty of Medicine, \\ Ain Shams University, Cairo, Egypt
}

\begin{abstract}
Backgrounds: Many surgical techniques have been described for management of grade III gynecomastia. Nippleareola complex (NAC) free transfer, inferior and superior pedicle techniques have been published in the literatures for treatment of grade III gynecomastia. In order to reduce the excess skin, all theses techniques leave acceptable scars. Original postero-inferior technique was described to improve the aesthetic outcome with preserving the neurovascular pedicle of the areola. This technique maintains the sensitivity and vitality of the new areola, but post-operative rates of breast contour and NAC were still not satisfactory. In this study, we described a new modified postero-inferior technique and compared its functional and aesthetic outcomes to that of the original technique.
\end{abstract}

Aim of this Study: Is to compare the functional and aesthetic outcomes as well as patients' satisfaction of the original and modified postero-inferior pedicle techniques in patients with grade III gynecomastia.

Patients and Methods: 12 adult patients suffering from grade III gynecomastia were included in this cohort prospective study. Patients were treated surgically by modified posteroinferior technique. Post-operative aesthetic and functional outcomes, as well as patients' satisfaction were evaluated by patients' questionnaires and compared to that of the original technique.

Results: In comparison to the original technique, aesthetic outcome of modified technique showed more patient satisfaction as regards chest contour (Q1) and NAC rating (Q2) with the same rate of patients' satisfaction as regards functional outcomes (nipple sensitivity and parathesia) also both techniques showed postoperative intact vascularity of the new NAC. Rate of complications decreased from 33\% in the original technique to $16.7 \%$ in the modified technique with $100 \%$ post-operative rate of NAC symmetry.

Conclusion: The new modified postero-inferior technique improves the post-operative aesthetic outcomes as well as it preserves the same functional outcomes, if compared with that of the original technique.

Key Words: Management - Gynecomastia - Pedicle.

\section{INTRODUCTION}

Gynecomastia is defined as either unilateral or bilateral benign hypertrophy of male mammary glands. It may be misdiagnosed with pseudogynecomastia, which is due to fat deposition deep to the areola with no gland hypertrophy [1]. In 2003, Rohrich and his colleagues classified gynecomastia according to physical examination into four grades; the first two grades having mild to moderate hypertrophy respectively, but without ptosis, while the last two grades showing severe hypertrophy with grade I ptosis in grade III gynecomastia, and grade II or III ptosis in grade IV gynecomastia [2]. Grade IV gynecomastia is mainly encountered in patients due to either overweight or following massive weight loss [3]. However, less obvious scarring may be needed in the majority of cases of severe gynecomastia. The periareolar approach is not sufficient in most of cases of severe gynecomastia [4]. Periareolar approach can treat grade II with mild skin excess, but it seems very hard to deal with severe skin excess as in grades III and IV gynecomastia [5]. NAC free transfer, inferior and superior pedicle techniques have been mentioned in the literatures for treatment of grade III gynecomastia, in order to reduce the excess skin. All theses techniques leave an acceptable scar; in 2017, Thiénot and his colleagues [6] described a new surgical method using the postero-inferior pedicle, as an alternative surgical solution for management of patients with moderate ptosis (Grade IIb in Simon classification [7] or Grade III in Rohrich classification). In comparison with nipple-areolar complex free transfer, the advantage of this new technique is to preserve the neurovascular function of the NAC, as it maximizes the opportunity to keep NAC sensitivity and vascularity intact, minimizing the risk of hypopigmentation and patch effect of NAC by preserving the projection of the nipple [6]. While the principle disadvantage of this technique as described by Thiénot was the relatively wide and thick postero-inferior pedicle that may cause breast prolapse in the long term, the other disadvantages of this method were the increased 
operative time, and high risk of post-operative asymmetry if present preoperatively [6]. In our study, we made some modifications in the preoperative markings as well as some surgical steps in order to overcome the main two disadvantages of this technique.

Aim of this study: Is to compare the functional and aesthetic outcomes as well as patients' satisfaction of the original and modified postero-inferior pedicle techniques in patients with grade III gynecomastia.

\section{PATIENTS AND METHODS}

12 adult patients suffering from grade III gynecomastia were included in this cohort prospective study from June 2018 to November 2019 in El Demerdash, Ain Shams University Hospital. Patients with previous breast surgeries were excluded from our study.

Patients were treated surgically via our modified postero-inferior pedicle technique.

Epidemiological data like age, weight, height, body mass index (BMI) were documented and evaluated. During surgery; volume of liposuction, weight of excised tissue were detected. Postoperative complications were noted.

6 months postoperatively, all Patients rated their satisfaction by answering the following questionnaire [8]. [on a scale of 1 (worst result) to 5 (best result)]; (How would you rate your overall chest contour?); (How would you rate your nippleareola complex?); (Would you have this surgery again?); (Would you recommend it to a friend?); (Would you go shirtless in public?); (Do you have nipple sensitivity?); and (Do you experience strange feelings in the nipples, such as burning or shooting pains?).

In all patients, the postoperative distances from supra-sternal notch (SSN) to nipple areola complex (NAC) were measured and compared bilaterally for evaluation of NAC symmetry.

\section{Pre-operative Markings:}

Original technique:

Preoperative markings were performed while patient in standing position. The lower incision line is placed in the infra-mammary line, and then the expected amount excised tissue detected by using a pinch test (usually just superior to the NAC). Area of de-epithelialization representing the postero-inferior pedicle was drawn. Pedicle width measured to be at least $6 \mathrm{~cm}$ [9]. The new position of NAC was determined; Thiénot drew a point, A, over the clavicle $5 \mathrm{~cm}$ lateral to suprasternal notch. Then an oblique line extending from point A to the nipple was marked. The inferior border of the new NAC was marked $4 \mathrm{~cm}$ superior to the upper incision line [10] and $2 \mathrm{~cm}$ lateral to the oblique line. The new NAC was drawn to be $2.5 \mathrm{~cm}$ in diameter (Fig. 1).

\section{Modified technique:}

In the original technique of Thiénot [6], NAC new position depends on two non anatomical lines; oblique line $5 \mathrm{~cm}$ from supra-sternal notch to the nipple, and horizontal line representing the expected upper excision line. The oblique line depending on the nipple position which can be different even in the same patient and the horizontal line is the expected line of excision that can be changed intraoperatively according to the excess skin.

We made two main modifications in the preoperative markings; first we reduced the pedicle width to be $4 \mathrm{~cm}$ rather than $6 \mathrm{~cm}$ in the original technique, in order to decrease the width of the flap and hence the postoperative projection of the breast (Fig. 2), second we drew of the new NAC intraoperative as we depend on two anatomical lines; vertical mid-clavicular which drawn preoperatively, and horizontal inframammary line (Incision line). First we checked the bilateral symmetry of level of both Inframammary line from SSN at the level of mid-clavicular, then the new NAC was centralized on both sides of mid-clavicular line and its lower border $2 \mathrm{~cm}$ above the inframammary line (incision line). The new NAC was drawn to be $3 \mathrm{~cm}$ in diameter. The new NAC was drawn intraoperative after skin closure by subcutaneous sutures to ensure its accurate position after maximum excision of the excess skin (Fig. 3).

\section{Modified surgical technique:}

Operation was done under general anesthesia while patient in supine position and arms were abducted at $90^{\circ}$. An adrenaline/Ringer's Lactate Solution, $(1: 100,000)$ was infiltrated. Liposuction was performed first superior to the area of excision by using a 4-mm cannula in order to reduce the layer of fat at the superior quadrants and also to achieve liposuction undermining. De-epithelialization of the pedicle in area surrounding the areola to the inframammary fold was performed (Fig. 4). We started our incision around the pedicle to the deep pectoral fascia to separate the whole pedicle from the ellipse of excision and to ensure that the pedicle was not separated from the underlying deep fascia in order to preserve its posterior blood supply. Then incision extended to the lower incision line 
(infra-mammary fold) sparing the $4 \mathrm{~cm}$ width of the pedicle. We started undermining of the ellipse by electro-cautery over the pectoral fascia and extended to the superior quadrants in the area of liposuction, this allows mobilization the upper thoracic skin to reach the infra-mammary line (Fig. 5).

After doing proper homeostasis by using electro-cautery, vertical incision was performed in the superior thoracic skin along the mid-clavicular line to approximate the superior and inferior skin as much as possible till there was no excess skin, and then stay suture was performed to close the superior and inferior skin properly. Excision of both sided of the superior skin was performed. Stay suture was then removed, and the pedicle was sutured to the pectoral fascia by absorbable vicryl 1 sutures
(Fig. 6), followed by deep subcutaneous closure of the incision line by using vicryl 0 sutures.

Intraoperative marking of the new NAC was done as mentioned before (Fig. 7), then round skin incision was performed, removing the skin and subcutaneous fat of the upper thoracic skin, and then the NAC was transposed (Fig. 8).

Finally, the NAC was sutured by 3-0 vicryl subcutaneous stitches followed by intradermal suturing by 4-0 monocryl thread. Two suction drains were introduced bilaterally; a three-plane suturing was done for the incision line; deep stitches with vicryl 0 absorbable thread, subcutaneous 30 vicryl sutures, and intradermal skin closure by 4-0 absorbable monocryl suture. We recommend compression garment to be applied for 2 months post-operatively.
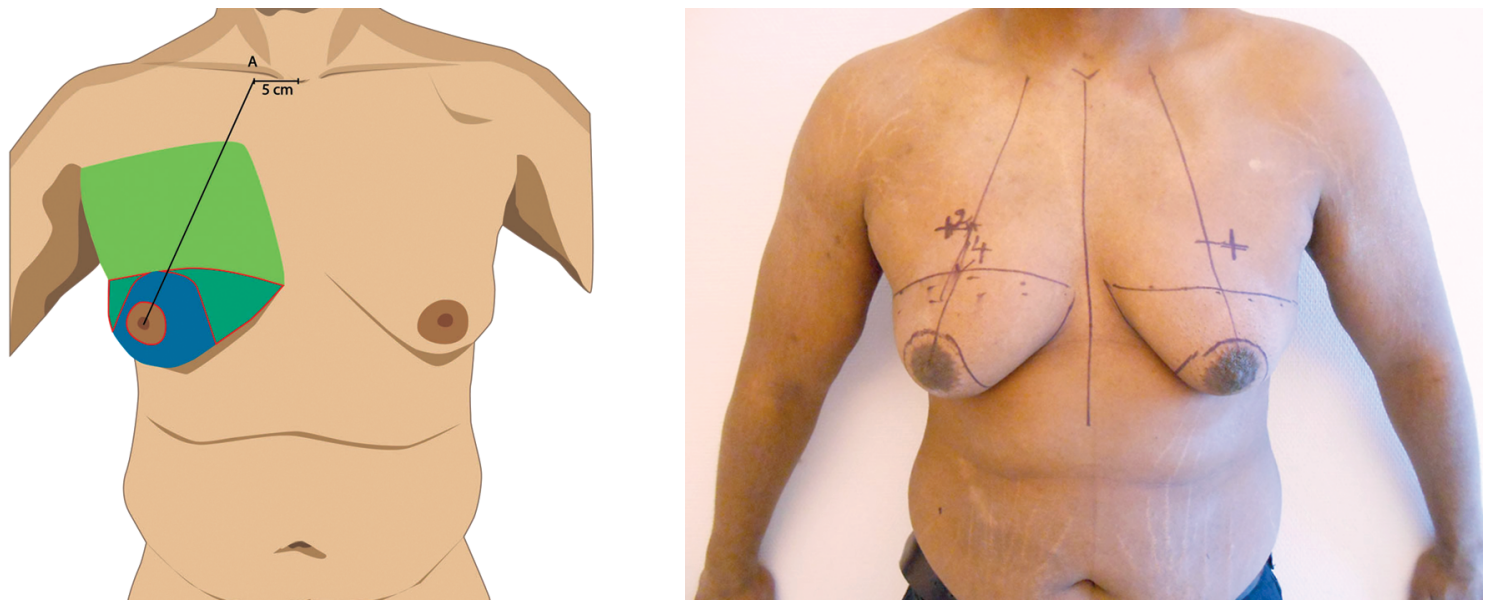

Fig. (1): Pre-operative markings of the original postero-inferior pedicle technique [6].

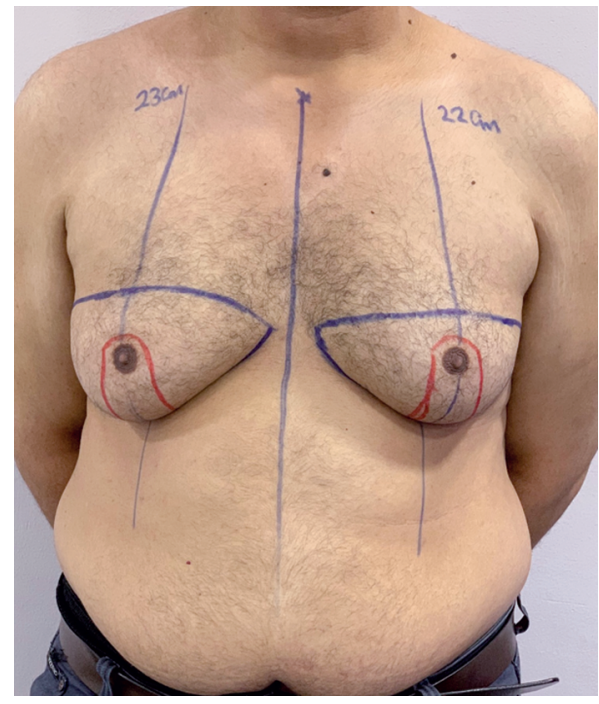

Fig. (2): Pre-operative markings (Pedicle $4 \mathrm{~cm}$ ).

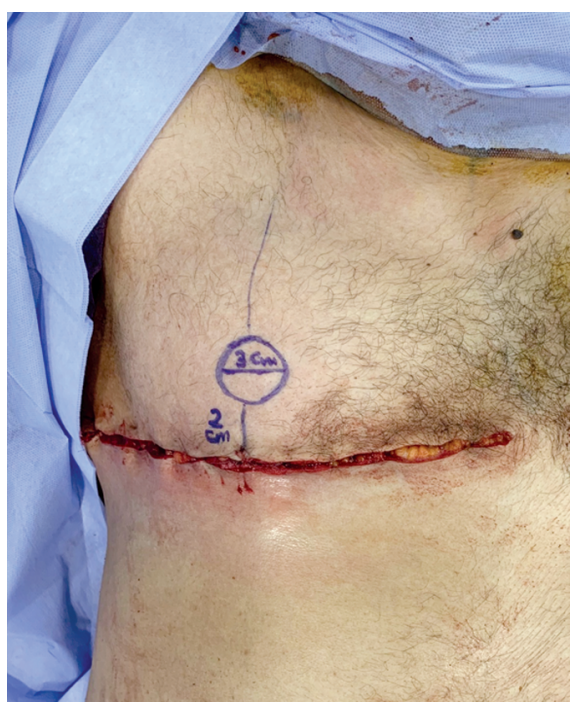

Fig. (3): Intra-operative new NAC markings. 


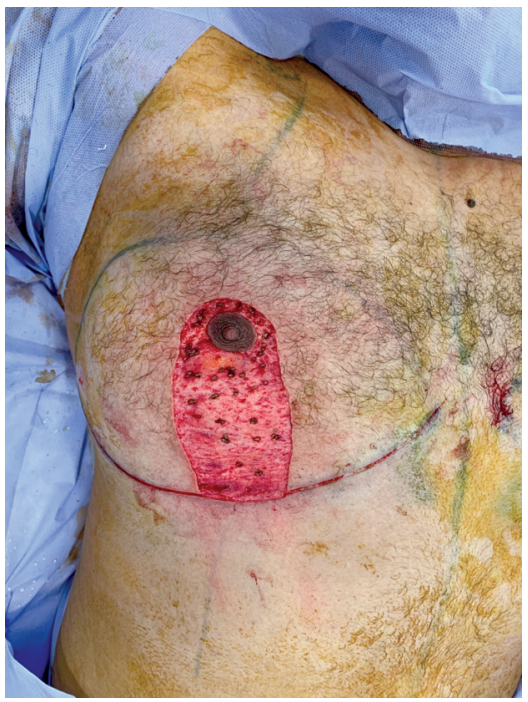

Fig. (4): Pedicle de-epithelialization.

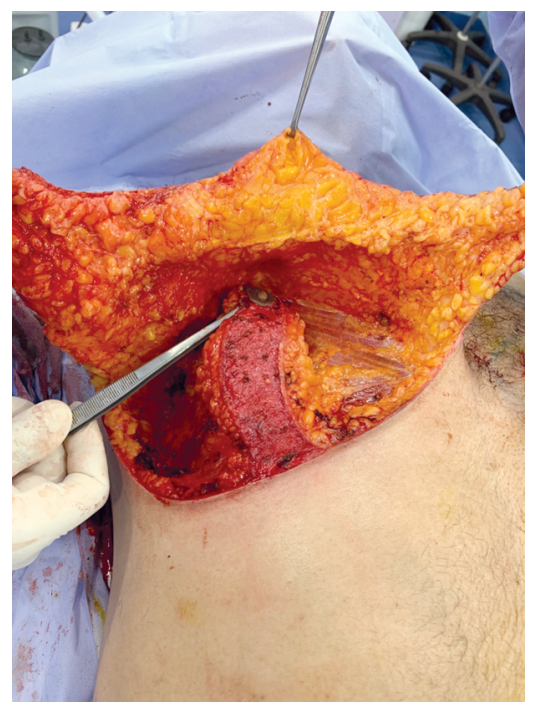

Fig. (5): Undermining of the superior skin.

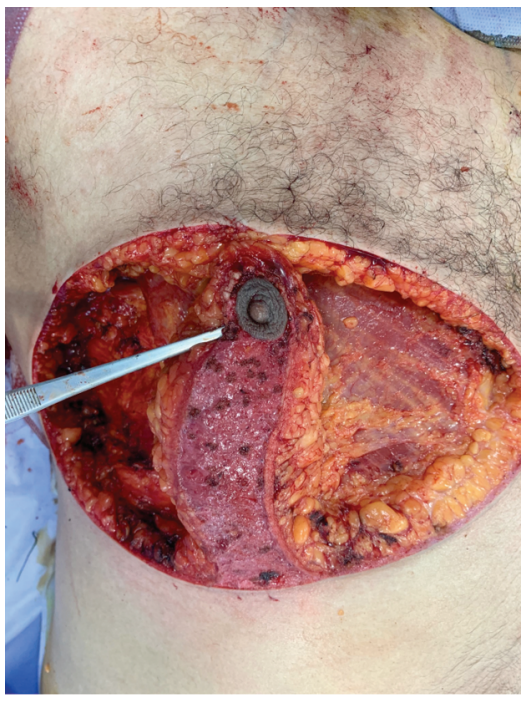

Fig. (6): Fixation of pedicle to the pectoral fascia.

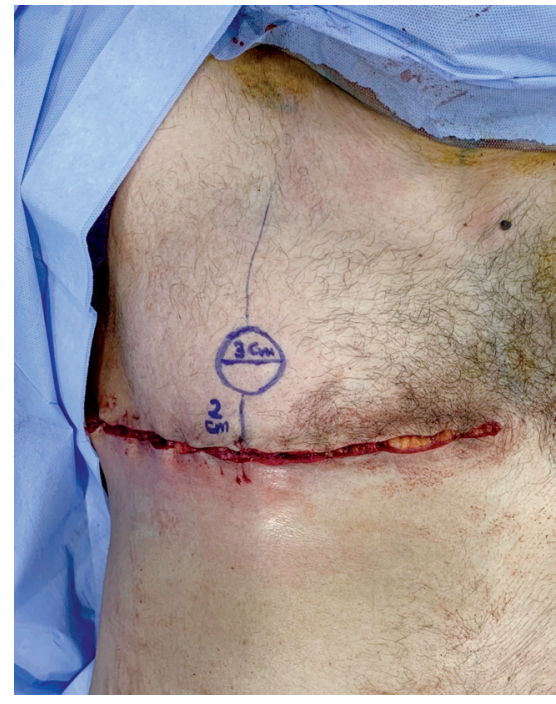

Fig. (7): Intra-operative new NAC markings.

\section{RESULTS}

This cohort prospective study included 12 patients that had undergone modified postero-inferior pedicle technique for management of grade III gynecomastia with mean age $33.5 \pm 9.6$ years and (range 18-48 years) and mean of BMI was 30.8 $2.1 \mathrm{~kg} / \mathrm{m}^{2}$ (range $\left.28-34 \mathrm{~kg} / \mathrm{m}^{2}\right)$.

The average volume of liposuction was $440 \pm$ $122 \mathrm{~mL}$ (range $250-650 \mathrm{~mL}$ ) and the average bilateral excision weight was $398 \pm 87.4 \mathrm{~g}$ (range $250-510 \mathrm{~g}$ ).

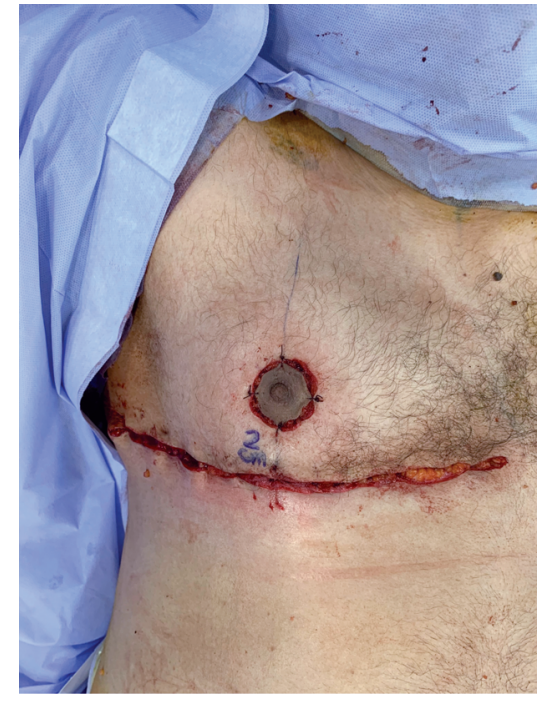

Fig. (8): Transposing the new NAC.

No major complications were occurred, some minor complications were detected in 2 patients (rate $16.7 \%$ ); one patient had $2 \mathrm{~cm}$ wound dehiscence of the transverse incision and healed by secondary intention, while the other one developed seroma which necessitated aspiration of $50 \mathrm{cc}$ once.

Data collected and compared with data of the original technique described by Thiénot [6]. (Table 1).

Table (1): Mean of Age, BMI, Liposuction Vol., Excision Wt. and complications rate in both techniques.

\begin{tabular}{llccc} 
& Mean age & Mean BMI & Complications rate & Mean liposuction volume \\
\hline Original technique & 42 years & $30.7 \mathrm{~kg} / \mathrm{m}^{2}$ & $33 \%$ & $633 \mathrm{~mL}$ \\
Modified technique & 33.5 years & $30.8 \mathrm{~kg} / \mathrm{m}^{2}$ & $16.7 \%$ & $586 \mathrm{~g}$ \\
\hline
\end{tabular}




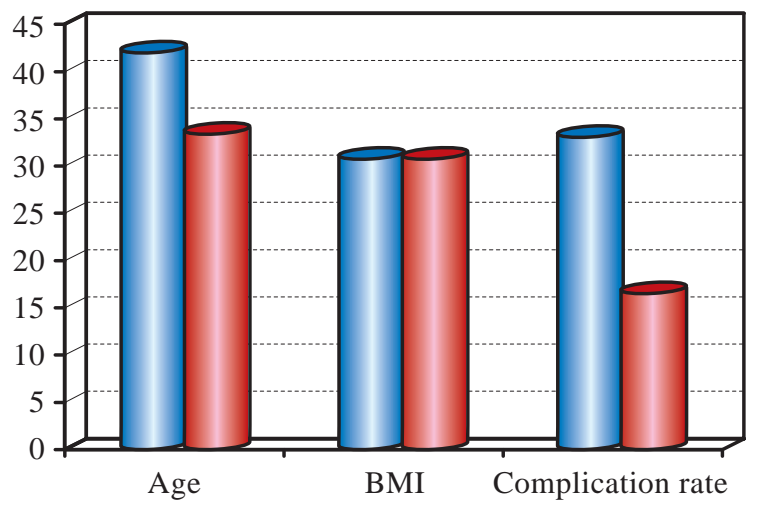

Original technique $\square$ Modified technique

Fig. (9): Mean of Age, BMI and Complication Rate in both techniques.

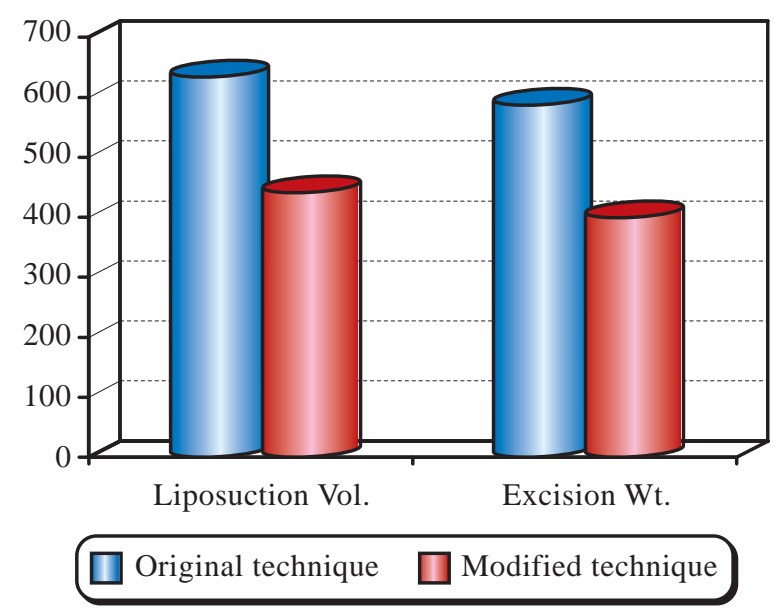

Fig. (10): Mean of Liposuction volume and Excision weight in both techniques.

Data collected from our patients by answering questionnaires was evaluated (Table 2) and compared to data described in Thiénot original article [6]. (Table 3).

Table (2): Data collected by answering questionnaires in our study.

\begin{tabular}{|c|c|c|c|c|c|c|c|}
\hline $\begin{array}{c}\text { Case } \\
\text { No. }\end{array}$ & Q1 & Q2 & Q3 & Q4 & Q5 & Q6 & Q7 \\
\hline 1 & 5 & 5 & Yes & Yes & Yes & Yes & No \\
\hline 2 & 5 & 5 & Yes & Yes & Yes & Yes & No \\
\hline 3 & 4.5 & 4 & Yes & Yes & Yes & Yes & No \\
\hline 4 & 4 & 4 & No & No & Yes & Yes & No \\
\hline 5 & 3.5 & 5 & Yes & Yes & No & Yes & No \\
\hline 6 & 5 & 4 & Yes & Yes & Yes & Yes & No \\
\hline 7 & 4 & 4 & Yes & Yes & Yes & Yes & No \\
\hline 8 & 3 & 5 & Yes & Yes & Yes & Yes & No \\
\hline 9 & 4 & 4.5 & Yes & Yes & Yes & Yes & No \\
\hline 10 & 5 & 5 & Yes & Yes & Yes & Yes & Yes \\
\hline 11 & 5 & 4 & Yes & Yes & Yes & Yes & No \\
\hline \multirow[t]{5}{*}{12} & 4.5 & 4 & Yes & Yes & Yes & Yes & No \\
\hline & SD & SD & Rate & Rate & Rate & Rate & Rate \\
\hline & 0.678401 & 0.498102 & $91.67 \%$ & $91.67 \%$ & $91.67 \%$ & $100 \%$ & $8.3 \%$ \\
\hline & Mean & Mean & & & & & \\
\hline & 4.375 & 4.458333 & & & & & \\
\hline
\end{tabular}

Q1: How would you rate your overall chest contour? [8].

Q2: How would you rate your nipple-areola complex?

Q3: Would you have this surgery again?

Q4: Would you recommend it to a friend?

Q5: Would you go shirtless in public?

Q6: Do you have nipple sensitivity?

Q7: Do you experience strange feelings in the nipples, such as burning or shooting pains?

Table (3): Comparison between data collected by original and modified techniques.

\begin{tabular}{lllccccc} 
& Q1 & Q2 & Q3 & Q4 & Q5 & Q6 & Q7 \\
\hline $\begin{array}{l}\text { Original } \\
\text { Technique }\end{array}$ & 4 & 4 & $91.67 \%$ & $91.67 \%$ & $100 \%$ & $100 \%$ & $8.3 \%$ \\
$\begin{array}{l}\text { Modified } \\
\text { Technique }\end{array}$ & 4.375 & 4.458 & $91.67 \%$ & $91.67 \%$ & $91.67 \%$ & $100 \%$ & $8.3 \%$ \\
\hline
\end{tabular}

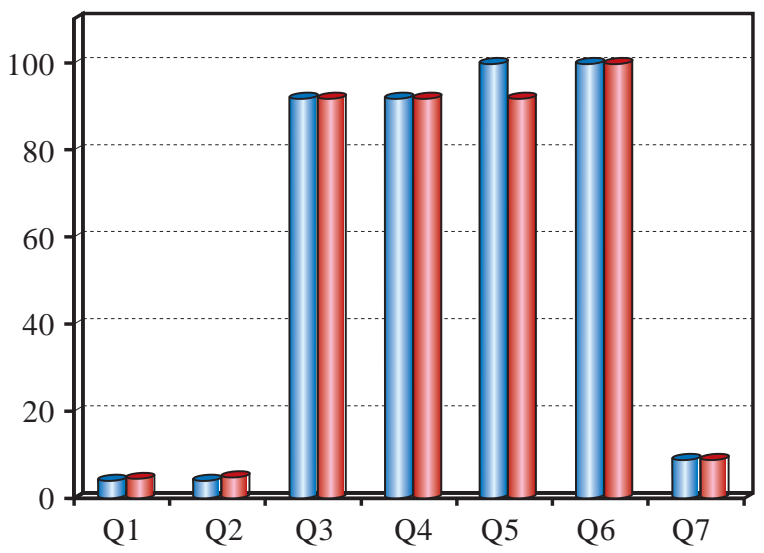

Original technique $\square$ Modified technique

Fig. (11): Comparison between data collected by original and modified techniques.

In our study, we add an objective method the ensure bilateral symmetry of the new NAC, all patients showed $100 \%$ post-operative bilateral symmetry rate of both NAC (Equal distance between SSN to new NAC bilaterally).

In comparison to the original technique, aesthetic outcome of modified technique showed more patient satisfaction as regards chest contour (Q1) and NAC rating $(\mathrm{Q} 2)$ with the same rate of patient satisfaction as regards functional outcomes (nipple sensitivity and parathesia) also, both techniques showed post-operative intact vascularity of the new NAC. 


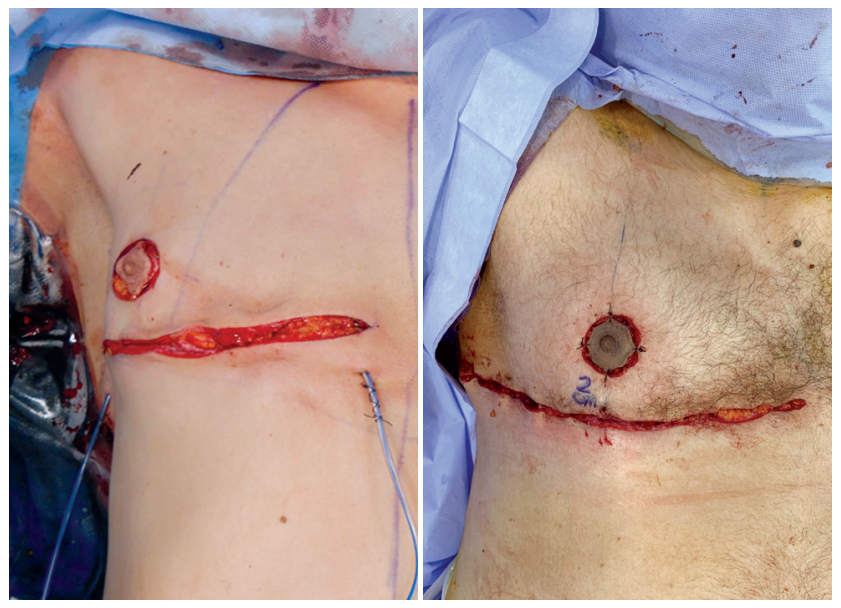

Fig. (12): Original technique Showed lateral displacement of new NAC (Left photo) [6] Modified technique showed normal position of new NAC (Right photo) (Intra-operative View).

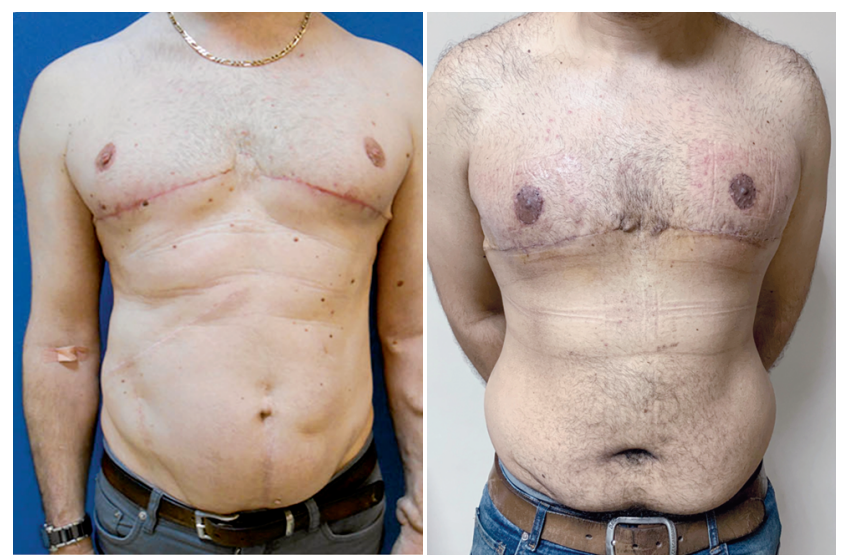

Fig. (13): Original technique showed upward displacement of the new NAC (Left photo) [6] Modified technique showed normal position of the new NAC (Right photo) (Frontal View).
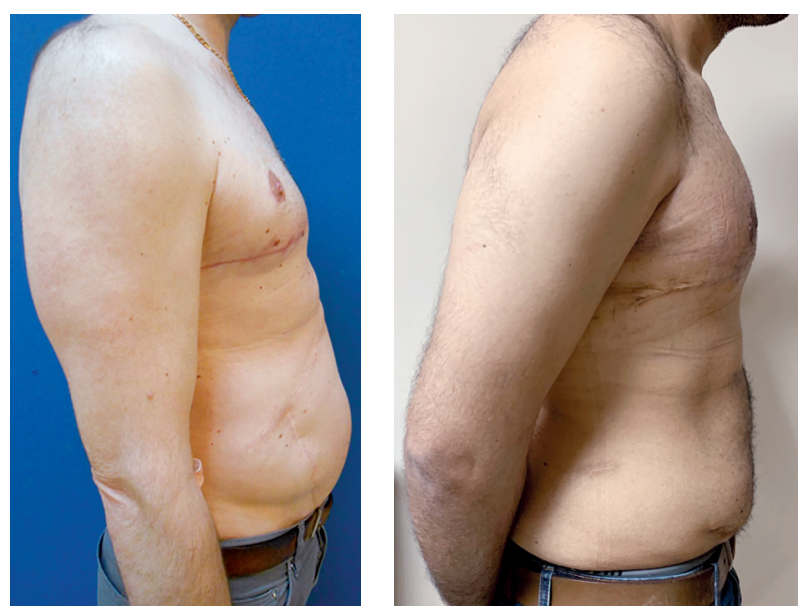

Fig. (14): Original technique showed upward displacement of the new NAC (Left photo) [6] Modified technique showed normal position of the new NAC (Right photo) (Lateral View).

Modified Postero-inferior pedicle technique (Case 1)

Pre-operative
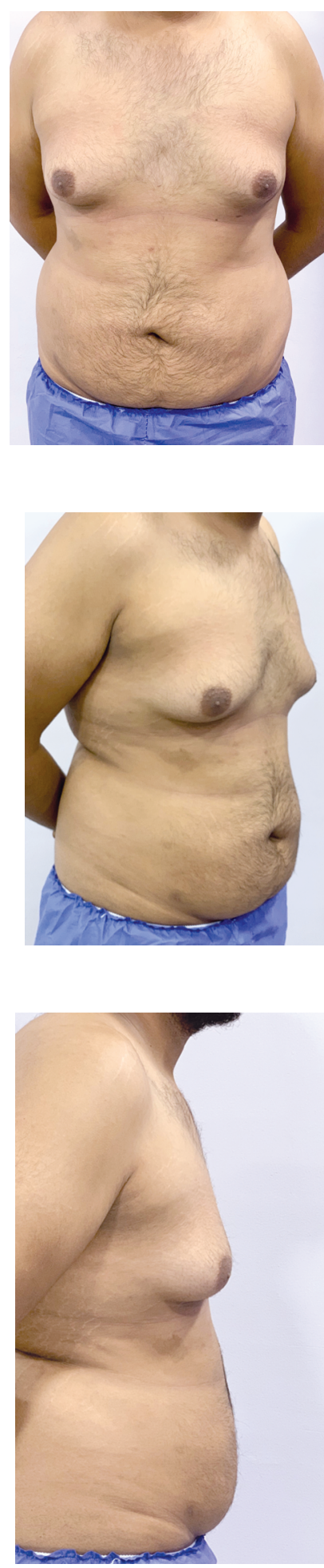

Post-operative
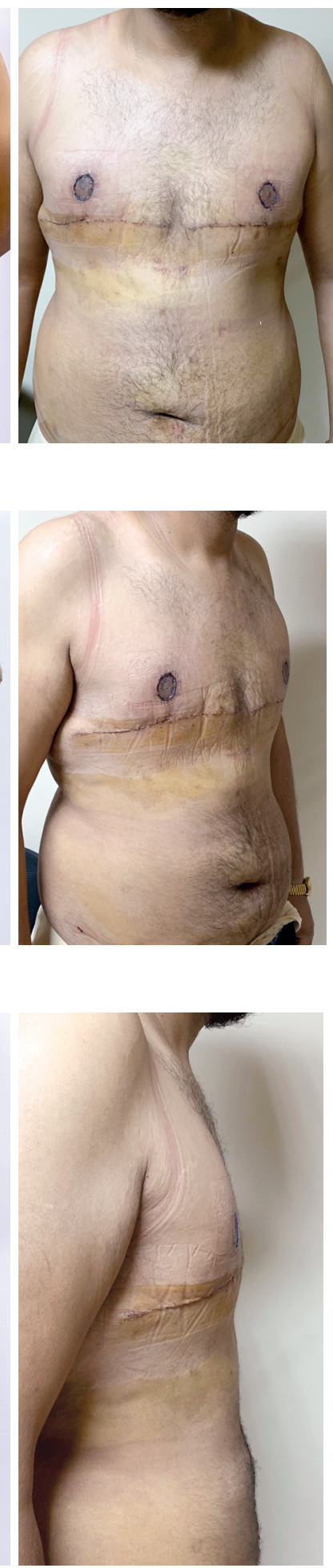
Modified Postero-inferior pedicle technique (Case 1)

Pre-operative
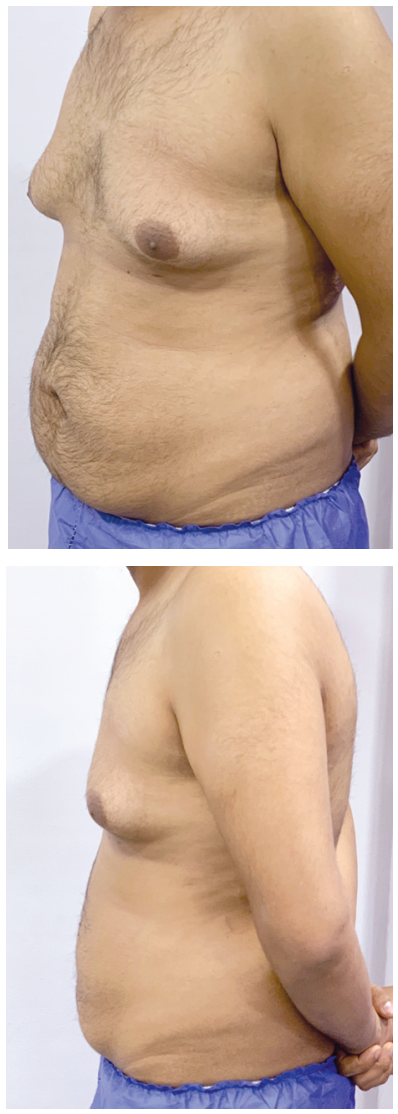

Modified Postero-inferior pedicle technique (Case 2) Pre-operative

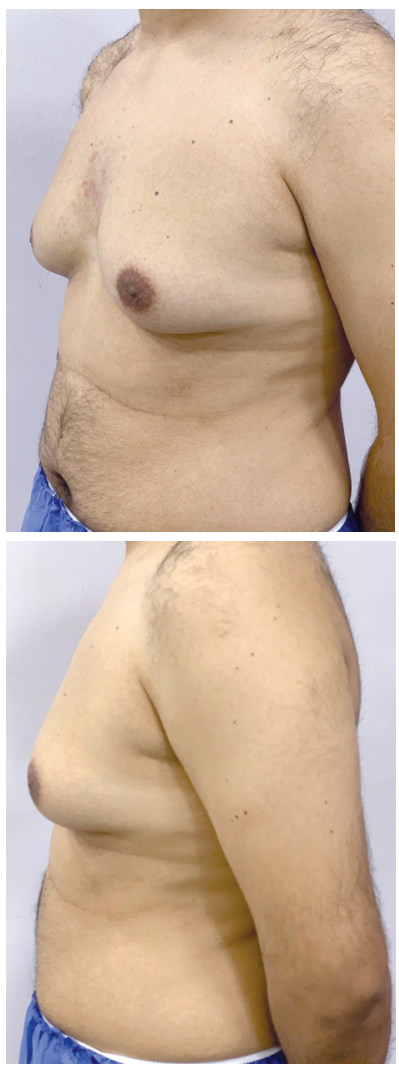

Post-operative
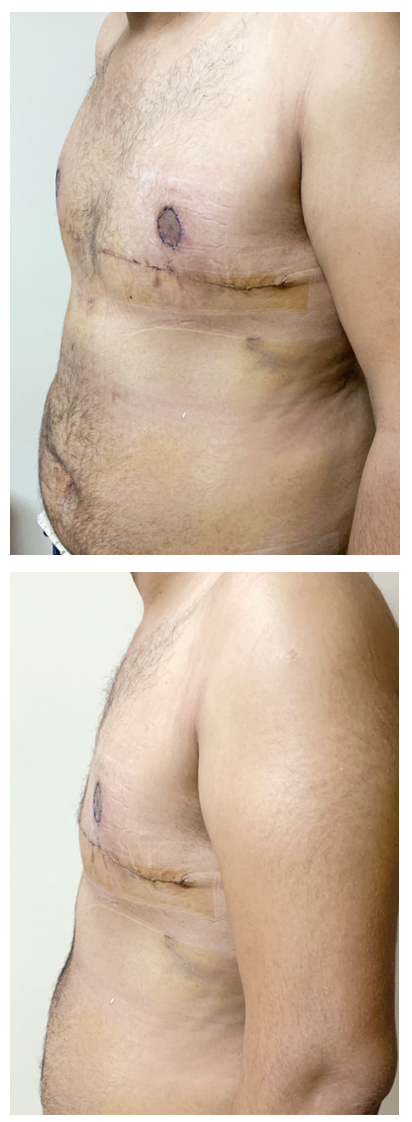

Post-operative

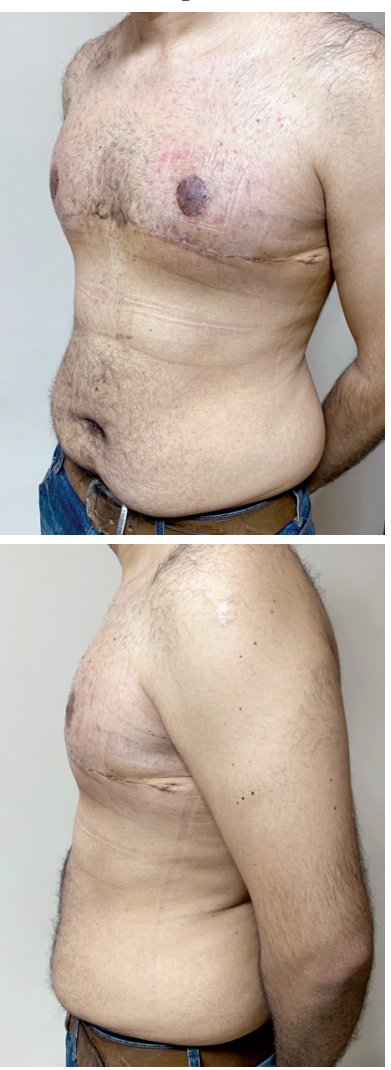

Modified Postero-inferior pedicle technique (Case 2)
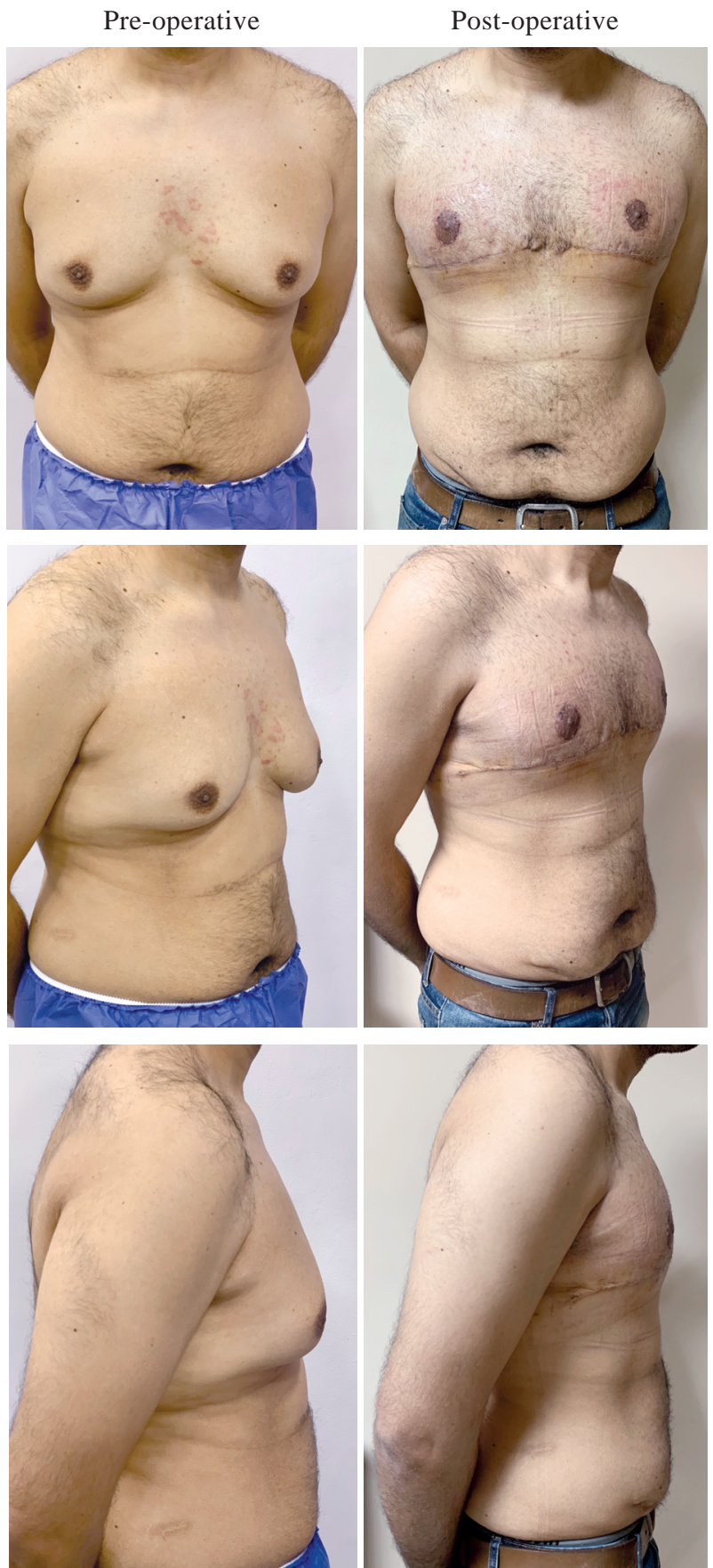

DISCUSSION

Many surgical techniques have been described for management of grade III gynecomastia; NAC free transfer is one of the most common surgical techniques used for treatment of grade III gynecomastia [3]. The main advantages of this technique are short operative time, easy repositioning if the NAC, excellent exposure and maximum glandular tissue resection that minimizes the postoperative chest projection, while its disadvantages are loss of NAC sensitivity, increase the incidence of NAC 
necrosis and hypopigmentation, patch effect of NAC and increased time of NAC healing [3,9,11]. Therefore many other surgical methods have been published to preserve the neurovascular pedicle of NAC and hence retaining its vitality and sensitivity. Superior pedicle technique is used by lifting a superior based flap with resection of the rest of gland, although this technique preserves the NAC sensitivity and vascularity, but it ends up by inverted T scar which is not accepted in males [10]. In 2008, Gheita [9] described a new superiorly based flap technique in which, the transverse incision was placed $6 \mathrm{~cm}$ superior the inframammary line with NAC in the center of the scar in order to avoid the vertical scarring, but the aesthetic results were unpleasant and the folded superior flap increases the breast projection, so inferior pedicle technique can overcome this complication by avoiding flap folding, and preserving the NAC functions with an acceptable only horizontal scarring. Although, in patients with grade IV gynecomastia, this technique will not be applicable as the length of inferior pedicle increases which will increase the risk of NAC necrosis, so in these patients, free NAC transplantation is recommended $[\mathbf{8 , 1 1}]$.

In 2017, the postero-inferior pedicle technique was described by Thiénot [6], this technique increased the new NAC safety over the previously described techniques, but the rates of postoperative breast contour and new NAC patient satisfaction were still not satisfactory, so in our study, we described this new modified technique to improve the post-operative patients' satisfaction with preserving the same NAC safety. In comparison with the original postero-inferior technique, our new modified technique showed more increase in the mean of postoperative patient satisfaction to breast contour (Q1) (4 in the original technique and 4.375 in the modified one) as well as more increase in mean of the NAC patient satisfaction (Q2) (4 in the original technique and 4.458 in the modified one), while the other rates of NAC functions (Q6 and 7) were the same, moreover the rate of complications decreased from $33 \%$ in the original technique to $16.7 \%$ in the new modified technique.

Rate of bilateral NAC symmetry was $100 \%$, as we prefer to draw the new NAC intraoperative after complete excision of the excess skin; this will ensure more accuracy of the new position of NAC in male breast. On contrary of the original technique that depended on two non anatomical lines in determining the position of the new NAC, our modified technique depended on two fixed anatomical lines (inframammary and mid-clavicular lines) that increased the rate of NAC symmetry post-operatively, as this wouldn't be affected by the position of the preoperative NAC or any underlying asymmetry. Also we reduced the width of the pedicle to be $4 \mathrm{~cm}$ rather than $6 \mathrm{~cm}$ in the original technique which improved the rate of patients' satisfaction to breast contour with preserving the vitality and sensitivity of the new NAC.

\section{Conclusion:}

The new modified postero-inferior technique improves the postoperative aesthetic outcomes as well as it preserves the same functional outcomes, if compared with that of the original technique.

\section{Recommendations:}

We recommend performing this new modified technique for patients with grade III gynecomastia to improve the post-operative aesthetic and functional outcomes, and performing free transplantation of NAC technique for patients with grade IV gynecomastia.

\section{REFERENCES}

1- Fabié-Boulard A., Fabre G., Gangloff D., Grolleau J-L. and Chavoin J-P.: Gynécomastie. EMC Tech Chir Plast Reconstr Esthét, 2013831-9 Artic 45-668-D 45 (668-D): $1-7,2013$

2- Rohrich R.J., Ha R.Y., Kenkel J.M., et al.: Classification and management of gynecomastia: Defining the role of ultrasound-assisted liposuction. Plast. Reconstr. Surg., 111: 909-923, 2003.

3- Bonte A.: Gynécomastie: Techniques chirurgicales et indications. EMC Tech Chir Plast Reconstr Esthét, 2013831-9 Artic 45-668-D. 45 (668-D): 1-9, 2013.

4- Huang T.T., Hidalgo J.E. and Lewis S.R.: A circumareolar approach in surgical management of gynecomastia. Plast. Reconstr. Surg., 69 (1): 35-40, 1982.

5- Innocenti A., Melita D., Mori F., Ciancio F. and Innocenti M.: Management of gynecomastia in patients with different body types: Considerations on 312 consecutive treated cases. Ann Plast Surg., 78 (5): 492-6, 2017.

6- Sophie Thiénot, Nicolas Bertheuil, Raphaël Carloni, Cécile Méal, Sylvie Aillet, Christian Herlin and Eric Watier: Postero-Inferior Pedicle Surgical Technique for the Treatment of Grade III Gynecomastia. Aesthetic Plast. Surg., 41 (3): 531-541, 2017.

7- Simon B.E., Hoffman S. and Kahn S.: Classification and surgical correction of gynecomastia. Plast. Reconstr. Surg., 51 (1): 48-52, 1973.

8- Gusenoff J.A., Coon D. and Rubin J.P.: Pseudogynecomastia after massive weight loss: Detectability of technique, patient satisfaction, and classification. Plast. Reconstr. Surg., 122 (5): 1301-1311, 2008.

9- Gheita A.: Gynecomastia: The horizontal ellipse method for its correction. Aesthetic Plast. Surg., 32 (5): 795-801, 2008. 
10- Wray R.C., Hoopes J.E. and Davis G.M.: Correction of extreme gynaecomastia. Br. J. Plast. Surg., 27 (1): 39-41, 1974.

11- Maetz B., Bodin F., Abbou R., Wilk A. and Bruant-Rodier C.: Management of weight loss consequences in the male chest: The amputation grafting technique with a $\mathrm{L}$ scar. Ann. Chir. Plast. Esthét, 58 (6): 650-657, 2013.
12- Mojallal A., Comparin J.P., Voulliaume D., Chichery A., Papalia I. and Foyatier J.L.: Reduction mammaplasty using superior pedicle in macromastia. Ann. Chir. Plast. Esthet, 50 (2): 118-126, 2005.

13- Kornstein A.N. and Cinelli P.B.: Inferior pedicle reduction technique for larger forms of gynecomastia. Aesthetic Plast. Surg., 16 (4): 331-335, 1992. 